\title{
CAUSES AND MANAGEMENT OF STRESS AT WORK
}

S Michie

S tress has been defined in different ways over the years. Originally, it was conceived of as pressure from the environment, then as strain within the person. The generally accepted definition today is one of interaction between the situation and the individual. It is the psychological and physical state that results when the resources of the individual are not sufficient to cope with the demands and pressures of the situation. Thus, stress is more likely in some situations than others and in some individuals than others. Stress can undermine the achievement of goals, both for individuals and for organisations (box 1).

Signs of stress can be seen in people's behaviour, especially in changes in behaviour.

Acute responses to stress may be in the areas of feelings (for example, anxiety, depression, irritability, fatigue), behaviour (for example, being withdrawn, aggressive, tearful, unmotivated), thinking (for example, difficulties of concentration and problem solving) or physical symptoms (for example, palpitations, nausea, headaches). If stress persists, there are changes in neuroendocrine, cardiovascular, autonomic and immunological functioning, leading to mental and physical ill health (for example anxiety, depression, heart disease) (box 2, fig 1). ${ }^{1}$

Situations that are likely to cause stress are those that are unpredictable or uncontrollable, uncertain, ambiguous or unfamiliar, or involving conflict, loss or performance expectations. Stress may be caused by time limited events, such as the pressures of examinations or work deadlines, or by ongoing situations, such as family demands, job insecurity, or long commuting journeys.

Resources that help meet the pressures and demands faced at work include personal characteristics such as coping skills (for example, problem solving, assertiveness, time management) and the work situation such as a good working environment and social support. These resources can be increased by investment in work infrastructure, training, good management and employment practices, and the way that work is organised.

Historically, the typical response from employers to stress at work has been to blame the victim of stress, rather than its cause. Increasingly, it is being recognised that employers have a duty, in many cases in law, to ensure that employees do not become ill. It is also in their long term economic interests to prevent stress, as stress is likely to lead to high staff turnover, an increase in sickness absence and early retirement, increased stress in those staff still at work, reduced work performance and increased rate of accidents, and reduced client satisfaction.

Good employment practice includes assessing the risk of stress amongst employees. This involves:

- looking for pressures at work which could cause high and long lasting levels of stress

- deciding who might be harmed by these

- deciding whether you are doing enough to prevent that harm.

\section{HOW STRESS IS CAUSED}

The degree of stress experienced depends on the functioning of two protective physiological mechanisms:

- "Alarm reaction". When confronted with a threat to our safety, our first response is physiological arousal: our muscles tense and breathing and heart rate become more rapid. This serves us well when the threat is the proverbial bull in the field rushing towards us. We either fight or flee. Present day threats tend to be more psychological—for example, unjustified verbal attack by a superior at work. It is usually not socially acceptable to act by "fight or flight", and an alternative means of expressing the resultant emotional and physical energy is required. This falls in the arena of assertive communication.

Correspondence to: Dr Susan Michie, Royal Free and University College Medical School, Pond Street, London NW3 2QG, UK; susan.michie@kcl.ac.uk

- "Adaptation". The second adaptive mechanism allows us to cease responding when we learn that stimuli in the environment are no longer a threat to our safety. For example, when we first spend time in a house near a railway line, our response to trains hurtling past is to be startled, as described above. Over time, our response dwindles. If this process did not function, we would eventually collapse from physical wear and tear, and mental exhaustion. 


\section{Box 1: The problem of stress}

\begin{tabular}{|c|c|}
\hline For the individual & For the workplace/organisation \\
\hline $\begin{array}{l}\text { Threats to: } \\
\text { - Health } \\
\text { - Well being/quality of life } \\
\text { - Functioning/goal } \\
\text { achievement } \\
\text { - Self esteem/confidence } \\
\text { - Personal development }\end{array}$ & $\begin{array}{l}\text { Increased absenteeism and turnover } \\
\text { Reduced quantity and quality of work } \\
\text { Reduced job satisfaction and morale } \\
\text { Problems of recruitment } \\
\text { Poor communication and increased } \\
\text { conflict }\end{array}$ \\
\hline
\end{tabular}

Stress is experienced when either of these mechanisms are not functioning properly or when we find it difficult to switch appropriately from one to another. This forms the basis of individual approaches to stress management (fig 2). Figure 2 shows that it is the perception, or appraisal, of the situation that is key to whether or not it causes stress. This is the basis of the transactional model of stress, ${ }^{2}$ whereby the ability of a person to prevent or reduce stress is determined by that person's appraisal of (a) the threat within a situation (primary appraisal), and (b) the appraisal of his/her coping skills to deal with that threat (secondary appraisal). These appraisals have been shaped by past experiences of confronting stress and, in turn, influence future behaviour and appraisals. Thus, the process of appraisal, behaviour, and stress is continuous, and managing stress can result from changing the way the situation is appraised (cognitive techniques) or responded to (behavioural or cognitive techniques).

\begin{tabular}{|c|c|}
\hline Box 2: Signs of stress & \\
\hline $\begin{array}{l}\text { How you feel (emotions) } \\
\text { - Anxious } \\
\text { - Depressed/tired } \\
\text { - Angry/irritable/frustrated } \\
\text { - Apathetic/bored }\end{array}$ & $\begin{array}{l}\text { How you think (cognitions) } \\
\text { Poor concentration and memory } \\
\text { Poor organisation and decision } \\
\text { making } \\
\text { Less creative in problem solving } \\
\text { Hypersensitive to criticism }\end{array}$ \\
\hline $\begin{array}{l}\text { How you behave } \\
\text { - Have accidents/make } \\
\text { mistakes } \\
\text { - Eating/sleeping problems } \\
\text { - Take drugs (e.g. tobacco, } \\
\text { alcohol) } \\
\text { - Problematic social behaviour } \\
\text { (e.g. withdrawal, aggression) }\end{array}$ & $\begin{array}{l}\text { Your body } \\
\text { Sweating, dizzy, nauseous, } \\
\text { breathless } \\
\text { Aches and pains } \\
\text { Frequent infections } \\
\text { Asthma, ulcers, skin complaints, } \\
\text { cardiac problems }\end{array}$ \\
\hline
\end{tabular}

\section{WORKPLACE FACTORS CAUSING STRESS}

The workplace is an important source of both demands and pressures causing stress, and structural and social resources to counteract stress.

The workplace factors that have been found to be associated with stress and health risks can be categorised as those to do with the content of work and those to do with the social and organisational context of work (fig 1). Those that are intrinsic to the job include long hours, work overload, time pressure, difficult or complex tasks, lack of breaks, lack of variety, and poor physical work conditions (for example, space, temperature, light).

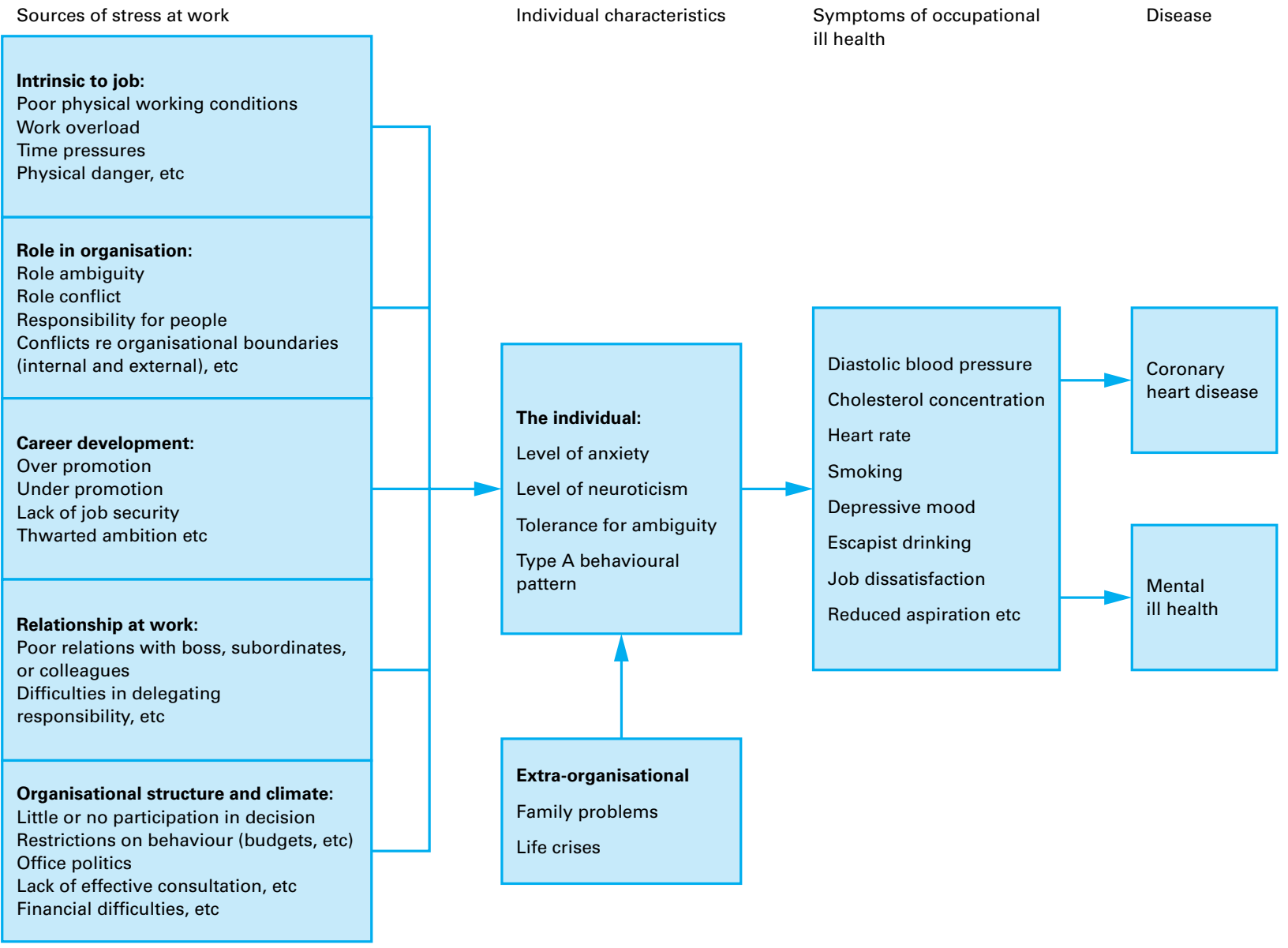

Figure 1 A model of stress at work.' 


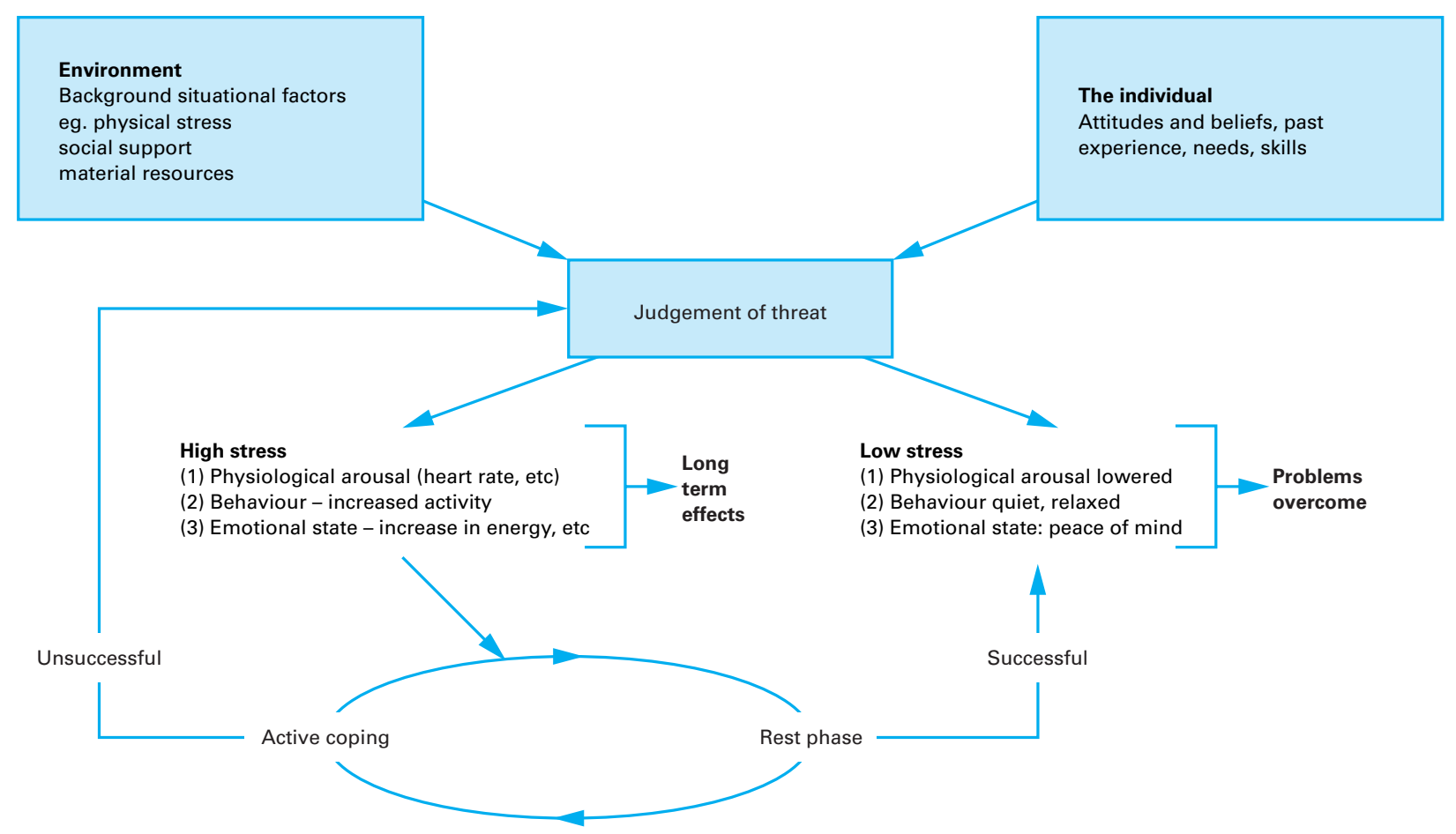

Figure 2 A model of stress and its management.

Unclear work or conflicting roles and boundaries can cause stress, as can having responsibility for people. The possibilities for job development are important buffers against current stress, with under promotion, lack of training, and job insecurity being stressful. There are two other sources of stress, or buffers against stress: relationships at work, and the organisational culture. Managers who are critical, demanding, unsupportive or bullying create stress, whereas a positive social dimension of work and good team working reduces it.

An organisational culture of unpaid overtime or "presenteeism" causes stress. On the other hand, a culture of involving people in decisions, keeping them informed about what is happening in the organisation, and providing good amenities and recreation facilities reduce stress. Organisational change, especially when consultation has been inadequate, is a huge source of stress. Such changes include mergers, relocation, restructuring or "downsizing", individual contracts, and redundancies within the organisation.

\section{Empirical review}

A systematic review of the evidence for work factors associated with psychological ill health and associated absenteeism $^{3}$ (Michie and Williams 2001, unpublished data) found the key factors to be:

- long hours worked, work overload and pressure

the effects of these on personal lives

- lack of control over work and lack of participation in decision making

- poor social support

- unclear management and work role and poor management style.

\section{Explanatory model}

Three of these factors form part of the influential controldemand model of work related strain. ${ }^{4}$ According to this model, work related strain and risks to health are most likely to arise when high job demands are coupled with low decision latitude (that is, low personal control over work and limited opportunities to develop skills). On the other hand, high job demands with high decision latitude gives the possibility of motivation to learn, active learning, and a sense of accomplishment. Of the two, decision latitude has been found to be more important than demand. ${ }^{5}$ Since its introduction in 1979, the model has been extended to include social support at work as a predictor of job strain. ${ }^{6}$ Karasek's model has received sufficient empirical support for it to provide a useful framework for interventions at work.

\section{INDIVIDUAL DIFFERENCES}

As is evident from figs 1 and 2, individuals differ in their risk of experiencing stress and in their vulnerability to the adverse effects of stress. Individuals are more likely to experience stress if they lack material resources (for example, financial security) and psychological resources (for example, coping skills, self esteem), and are more likely to be harmed by this stress if they tend to react emotionally to situations and are highly competitive and pressured (type A behaviour).

The association between pressures and well being and functioning can be thought of as an inverted $\mathrm{U}$, with well being and functioning being low when pressures are either high or very low (for example, in circumstances of unemployment). Different people demonstrate different shapes of this inverted $U$, showing their different thresholds for responses to stress. A successful strategy for preventing stress within the workplace will ensure that the job fits the person, rather than trying to make people fit jobs that they are not well suited to.

\section{INTERACTIONS BETWEEN WORK AND HOME STRESS}

Increasingly, the demands on the individual in the workplace reach out into the homes and social lives of employees. Long, uncertain or unsocial hours, working away from home, taking work home, high levels of responsibility, job insecurity, and job 


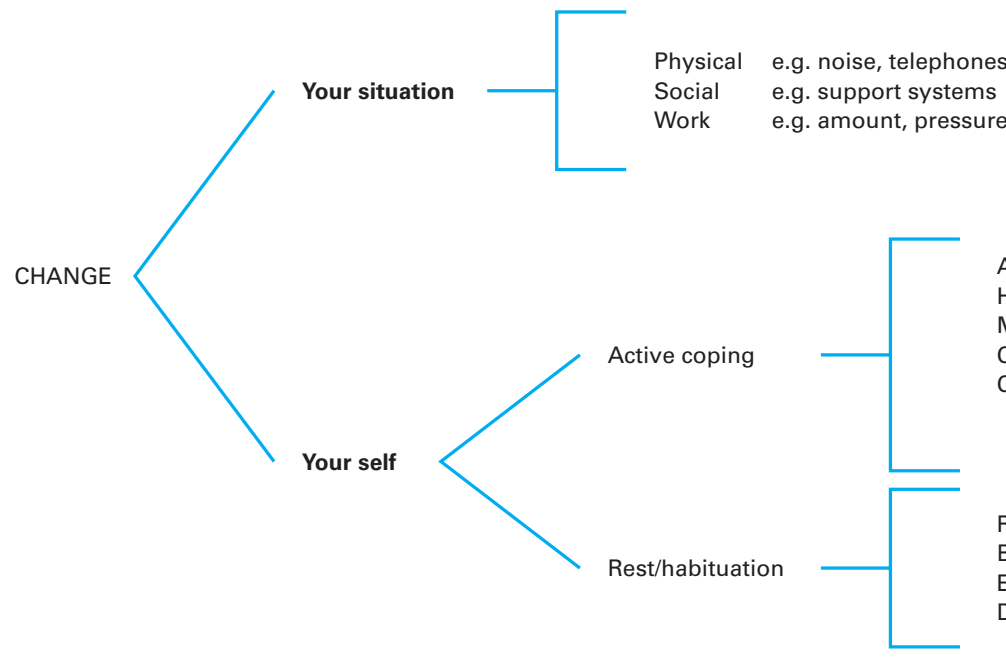

Assertiveness/social skills/communication Habits: eating, drinking, sleeping, smoking, exercise Managing time, priorities, delegation Control: self-monitoring, feedback

Cognitive: positive thinking/self talk/imagery pyschological preparation including information reappraisal - perception, interpretation

\section{Relaxation/yoga/meditation}

Break/leisure/holidays

Exercise

Distraction/denial/acceptance

Figure 3 Techniques for managing stress.

relocation all may adversely affect family responsibilities and leisure activities. This is likely to undermine a good and relaxing quality of life outside work, which is an important buffer against the stress caused by work. In addition, domestic pressures such as childcare responsibilities, financial worries, bereavement, and housing problems may affect a person's robustness at work. Thus, a vicious cycle is set up in which the stress caused in either area of one's life, work or home, spills over and makes coping with the other more difficult.

Women are especially likely to experience these sources of stress, ${ }^{7}$ since they still carry more of the burden of childcare and domestic responsibilities than men. In addition, women are concentrated in lower paid, lower status jobs, may often work shifts in order to accommodate domestic responsibilities, and may suffer discrimination and harassment

\section{INDIVIDUAL STRESS MANAGEMENT}

Most interventions to reduce the risk to health associated with stress in the workplace involve both individual and organisational approaches. Individual approaches include training and one-to-one psychology services-clinical, occupational, health or counselling. They should aim to change individual skills and resources and help the individual change their situation. The techniques listed in fig 3 mirror the active coping (fight/flight) and rest phases (habituation) of the stress model presented earlier.

Training helps prevent stress through:

- becoming aware of the signs of stress

- using this to interrupt behaviour patterns when the stress reaction is just beginning. Stress usually builds up gradually. The more stress builds up, the more difficult it is to deal with

- analysing the situation and developing an active plan to minimise the stressors

- learning skills of active coping and relaxation, developing a lifestyle that creates a buffer against stress

- practising the above in low stress situations first to maximise chances of early success and boost self confidence and motivation to continue.

A wide variety of training courses may help in developing active coping techniques-for example, assertiveness, communications skills, time management, problem solving, and effective management.
However, there are many sources of stress that the individual is likely to perceive as outside his or her power to change, such as the structure, management style or culture of the organisation. It is important to note that stress management approaches that concentrate on changing the individual without changing the sources of stress are of limited effectiveness, and may be counterproductive by masking these sources. For example, breathing deeply and thinking positively about a situation causing stress may make for a temporary feeling of well being, but will allow a damaging situation to continue, causing persistent stress and, probably, stress to others. The primary aim of the individual approach should be to develop people's skills and confidence to change their situation, not to help them adapt to and accept a stressful situation.

\section{ORGANISATIONAL STRESS MANAGEMENT}

The prevention and management of workplace stress requires organisational level interventions, because it is the organisation that creates the stress. An approach that is limited to helping those already experiencing stress is analogous to administering sticking plaster on wounds, rather than dealing with the causes of the damage. An alternative analogy is trying to run up an escalator that's going down! Organisational interventions can be of many types, ranging from structural (for example, staffing levels, work schedules, physical environment) to psychological (for example, social support, control over work, participation).

The emphasis on the organisation, rather than the individual, being the problem is well illustrated by the principles used in Scandinavia, where there is an excellent record of creating healthy and safe working environments ${ }^{3}$ (box 3 ).

Assessing the risk of stress within the workplace must take into account:

- the likelihood and the extent of ill health which could occur as a result of exposure to a particular hazard

- the extent to which an individual is exposed to the hazard

- the number of employees exposed to the hazard.

The analysis of stressful hazards at work should consider all aspects of its design and management, and its social and organisational context. ${ }^{9}$ Although the priority is prevention, protective measures can be introduced to control the risk and 
Box 3: Principles of preventing work stress in Scandinavia

- Working conditions are adapted to people's differing physical and mental aptitudes

- Employee is given the opportunity to participate in the design of his/her own work situation, and in the processes of change and development affecting his/her work

- Technology, work organisation, and job content are designed so that the employee is not exposed to physical or mental strains that may lead to illness or accidents. Forms of remuneration and the distribution of working hours are taken into account

- Closely controlled or restricted work is avoided or limited

- Work should provide opportunities for variety, social contact, and cooperation as well as coherence between different working operations

- Working conditions should provide opportunities for personal and vocational development, as well as for self determination and professional responsibility

\section{Box 4: A risk assessment strategy — six stages 9}

\section{- Hazard identification:}

Reliably identify the stressors which exist in relation to work and working conditions, for specified groups of employees, and make an assessment of the degree of exposure

- Assessment of harm:

Collect evidence that exposure to such stressors is associated with impaired health in the group being assessed or of the wider organisation. This should include a wide range of health-related outcomes, including symptoms of general malaise and specific disorders, and of organisational and health related behaviours such as smoking and drinking, and sickness absence

- Identification of likely risk factors:

Explore the associations between exposure to stressors and measures of harm to identify likely risk factors at the group level, and to make some estimate of their size and/or significance

- Description of underlying mechanisms:

Understand and describe the possible mechanisms by which exposure to the stressors is associated with damage to the health of the assessment group or to the organisation

- Audit existing management control and employee support systems:

Identify and assess all existing management systems both in relation to the control of stressors and the experience of work stress, and in relation to the provision of support for employees experiencing problems.

- Recommendations on residual risk:

Take existing management control and employee support systems into proper account, make recommendations on the residual risk associated with the likely risk factors related to work stress

reduce the effects of a given hazard. A detailed account of how to assess and reduce risk associated with exposure to stressful hazards is summarised in box 4 .

Increasingly, legislation requires employers to assess and address all risks to employee health and safety, including their mental health (for example, the European Commission's framework directive on the introduction of measures to encourage improvements in the safety and health of workers at work). Creating a safe system of work requires targeting equipment, materials, the environment and people (for example, ensuring sufficient skills for the tasks). It also requires having monitoring and review systems to assess the extent to which prevention and control strategies are effective. ${ }^{10}$

Although associations between workplace factors and psychological ill health and associated sickness absence have been well documented, evidence based interventions to reduce these problems are scarce. ${ }^{3}$

Successful interventions used training and organisational approaches to increase participation in decision making and problem solving, increase support and feedback and improve communication. ${ }^{11-16}$ These studies found that:

- those taught skills to mobilise support at work and to participate in problem solving and decision making reported more supportive feedback, feeling more able to cope, and better work team functioning and climate. Among those most at risk of leaving, those undergoing the training reported reduced depression ${ }^{12}$

- staff facing organisational change who were taught skills of stress management, how to participate in, and control, their work showed a decrease of stress hormone levels ${ }^{14}$

- staff taught verbal and non-verbal communication and empathy skills demonstrated reduced staff resignations and sick leave ${ }^{16}$

- physically inactive employees undergoing stress management training improved their perceived coping ability and those undergoing aerobic exercise improved their feelings of well being and decreased their complaints of muscle pain, but also reported reduced job satisfaction ${ }^{11}$

- employees undergoing one of seven training programmes emphasising one or more aspects of stress management-physiological processes, coping with people or interpersonal awareness processes-showed reductions in depression, anxiety, psychological strain, and emotional exhaustion immediately after the programme. There was a further reduction in psychological strain and emotional exhaustion at 9-16 months' follow $\operatorname{up}^{13}$

- those on long term sickness absence who were referred early to the occupational health department (within two or three months absence) reduced their sickness absence from 40 to 25 weeks before resumption of work and from 72 to 53 weeks before leaving employment for medical reasons, leading to large financial savings. ${ }^{15}$

Success in managing and preventing stress will depend on the culture in the organisation. Stress should be seen as helpful information to guide action, not as weakness in individuals. A culture of openness and understanding, rather than of blame and criticism, is essential. Building this type of culture requires active leadership and role models from the top of the organisation, the development and implementation of a stress policy throughout the organisation, and systems to identify problems early and to review and improve the strategies developed to address them. The policy and its implementation should be negotiated with the relevant trade unions and health and safety committees (for a trade union example of a model agreement for preventing stress at work see the Manufacturing, Science and Finance Union guide ${ }^{17}$ ).

Last, but by no means least, interventions should be evaluated, so that their effectiveness can be assessed. Ideally, the method of achieving this should include a high response rate, 
valid and reliable measures, and a control group. Two measures that provide a comprehensive analysis of work stress and have been widely used are the Job Content Questionnaire, which includes measures of the predictors of job strain described earlier, ${ }^{18}$ and the Occupational Stress Indicator. ${ }^{19}$

\section{REFERENCES}

1 Cooper CL, Marshall J. Occupational sources of stress: a review of the literature relating to coronary heart disease and mental ill health. J Occup Health Psychol 1976;49:11-28.

2 Lazarus S, Folkman S. Stress, appraisal and coping. New York: Springer, 1984.

- A comprehensive account of the transactional model of stress and its management.

3 Williams S, Michie S, Patani S. Improving the health of the NHS workforce. London: The Nuffield Trust, 1998

- A systematic review of the evidence of associations between work factors and ill health and of effective workplace interventions. References 11-16 are to the six effective interventions identified in this systematic review.

4 Karasek RA, Theorell T. Healthy work: stress, productivity, and the reconstruction of working life. New York: Basic Books, 1990.

- A seminal book that combines a clear theoretical and empirical approach to work stress.

5 Johnson JV, Stewart W, Friedlund P, et al. Long-term psychosocial work environment and cardiovascular mortality among Swedish men. Am J Public Health 1996;86,324-31.

6 Hall EM, Johnson JV. Depression in unemployed Swedish women. Soc Sci Med 1985;27:1349-55

7 Hall EM. Women, work and health: employment as a risk factor for coronary heart disease. J Prev Cardiol 1994;4:365-84.

8 Gardell B, Gustavsen B. Work environment research and social change: current developments in Scandinavia. J Occup Behav 1980;1:3-17.

9 Health and Safety Executive. Organisational interventions for work stress: a risk management approach. Norwich: Her Majesty's Stationery Office, 2000.

- A thorough guide as to how to apply a risk management approach to work stress.

10 Cox T, Griffiths A. The nature and measurement of work stress: theory and practice. In: Wilson JR, Corlett EN, et al, eds. Evaluation of human work: a practical ergonomics methodology, 2nd ed. London: Taylor \& Francis, 1995:783-803.

11 Gronningsaeter $\mathbf{H}$, et al. Improved health and coping by physical exercise or cognitive behavioral stress management training in a work environment. Psychology and Health 1992;7:147-63.

12 Heany CA, Price RH, Refferty J. Increasing coping resources at work: a field experiment to increase social support, improve work team functioning, and enhance employee mental health. J Organisational Behav 1995; 16:335-52.

13 Kagan NI, Kagan H, Watson MG. Stress reduction in the workplace: the effectiveness of psychoeducational programs. J Counselling Psychol 1995:42:71-8.

14 Lokk J, Arnetz B. Psychophysiological concomitants of organisational change in health care personnel: effects of a controlled intervention study. Psychother Psychosom 1997;66:74-7.

15 Malcolm RM, Harrison J, Forster $\mathrm{H}$. Effects of changing the pattern of referrals in a local authority. Occup Med 1993;43:21 1-15.

16 Smoot SL, Gonzales JL Cost-effective communication skills training for state hospital employees. Psychiatr Serv 1995;46:819-22.
17 Manufacturing, Science and Finance Union. Preventing stress at work: an MSF guide. London: MSF, 1997.

18 Karasek R, Brisson C, Kawakami N, et al. The job content questionnaire (JCQ): an instrument for internationally comparative assessment of psychosocial job characteristics. J Occup Health Psychol 1988;3:322-55.

19 Cooper CL, Sloan SJ, Williams S. Occupational stress indicator management guide. Windsor: NFER-Nelson, 1998.

\section{QUESTIONS (SEE ANSWERS ON P 8)}

(1) Stress is best seen as:

(a) pressures and demands put on an individual

(b) maladaptive responses of individuals-for example, anxiety, irritability, aches and pains

(c) an interaction between situational demands and the resources of the individual to cope with them

(d) a reaction that can be positive or negative, depending on the person and the situation

(e) a transactional process, whereby the ability of a person to prevent stress is determined by that person's appraisal of threat and his/her appraisal of his/her coping abilities

(2) The following are key dimensions of Karasek's model of job strain:

(a) job demands

(b) person-environment fit

(c) decision latitude

(d) role ambiguity

(e) social support

(3) The following are examples of active coping:

(a) problem solving

(b) distracting oneself from the problem

(c) assertive behaviour

(d) resting

(e) time management

(4) Individual approaches to stress management aim to:

(a) help the individual change their situation

(b) train skills

(c) change the sources of stress

(d) help develop people's confidence

(e) help people adapt to the stressful situation

(5) Organisational approaches to stress management:

(a) are analogous to putting a sticking plaster on a wound

(b) consider stress in terms of hazards

(c) depend on training

(d) are appropriate in a culture of blame and criticism

(e) include interventions designed to increase participation in decision making 